must, however, be mentioned that $C_{t}$ is not the only factor which has an effect on demulsification because, even at a constant value of $C_{t}$, yield increased with increasing stirring speed of homogenizer ${ }^{1)}$ and because demulsification did not occur without coexisting oil even at the value of $C_{t}$ shown in Fig. 6 .

Figure 6 also demonstrates that the yield of breaking strongly depends on the devices used in both emulsification and demulsification. When the stirring vessel (SV) was used as an emulsifier, the size distribution of oil droplets had a quite broad peak; the average diameter was about $10 \mu \mathrm{m}$. When highspeed homogenizers (HSH) were used, peaks were narrow; the mean value was about $2 \mu \mathrm{m}$ for $\mathrm{HSH}$ of standard type (type A) and about $1 \mu \mathrm{m}$ for improved type (type B). As might be expected, the emulsions which had smaller oil droplets were more stable during demulsification, while the demulsifiers that exerted strong agitation could demulsify emulsions more efficiently.

\section{Acknowledgment}

A part of this work was supported by a Grant-in-Aid for
Scientific Research (No. 61303014) from the Ministry of Education, Science and Culture of Japan.

$$
\begin{aligned}
& \text { Nomenclature } \\
& C_{s}=\text { concentration of saponin in membrane } \\
& \text { solution } \\
& {[\mathrm{wt} \%]} \\
& C_{t}=\text { concentration of saponin in total } \\
& \text { liquid mixture } \\
& N \quad=\text { stirring speed } \\
& Q_{\text {ow } 1} \quad=\text { volumetric flow rate of } \mathrm{O} / \mathrm{W} \text { emulsion } \\
& \text { flowing into cell } \\
& =\text { volumetric flow rate of } \mathrm{O} / \mathrm{W} \text { emulsion } \\
& \text { flowing out of cell } \\
& =\text { volumetric flow rate of aqueous } \\
& \text { membrane solution } \\
& =\text { mean residence time in flow cell } \\
& =\text { yield of demulsification defined by Eq. (1) } \\
& =\text { volume fraction of coexisting oil } \\
& \text { in premixer } \\
& =\text { volume fraction of aqueous membrane } \\
& \text { solution in original } \mathrm{O} / \mathrm{W} \text { emulsion } \\
& {\left[\mathrm{m}^{3}\right]}
\end{aligned}
$$

\section{Literature Cited}

1) Kato, S. and J. Kawasaki: J. Chem. Eng. Japan, 20, 232 (1987).

\title{
DENSITY-DEPENDENT LOCAL-COMPOSITION EFFECTS ON MIXING RULE OF CUBIC EQUATIONS OF STATE
}

\author{
XI-YIN ZHENG, GUANG-Wen WU AND NAI-WEN ZHANG \\ Department of Chemical Engineering, Dalian University of Technology, People's Republic of China
}

\begin{abstract}
Key Words: Equation of State, Phase Equilibrium, Local Composition Model, Mixing Rule, Thermodynamics, Unified Model
\end{abstract}

\section{Introduction}

The density-dependent local-composition model combined with equations of state seems rather promising for describing the phase behavior of strongly nonideal mixtures at high pressure. Attention has recently been focused on computer simulation to investigate the validity of the local composition model. ${ }^{1-3,5-7)}$ However, most computer simulation data are limited to simple mixtures. It is rather difficult to explain the complex molecular interactions in polar or associated mixtures.

The density-dependent local mole fractions of the

Received September 10, 1987. Correspondence concerning this article should be addressed to $X$. Y. Zheng. unified model proposed in our previous work ${ }^{15)}$ are defined as:

$$
\begin{aligned}
& x_{12}=x_{1} E_{12} /\left(x_{1} E_{12}+x_{2}\right) \\
& x_{21}=x_{2} E_{21} /\left(x_{1}+x_{2} E_{21}\right) \\
& x_{11}+x_{21}=1, \quad x_{12}+x_{22}=1
\end{aligned}
$$

where $E_{i j}$ 's are designated as nonconformal parameters, representing the deviation from the conformal reference state.

Its definition can be expressed as:

$$
E_{i j}=\exp \left[-C_{i j} a_{i j}^{o} f(v) / R T\right]
$$

where: $C_{i j}$ 's are binary interaction parameters. $a_{i j}^{o}$ is the attractive constant for the $i-j$ pair in the 
conformal mixture. $f(v)$ is a function of volume. $v$ in $f(v)$ is obtained by solving the proposed DDLC-SRK equation.

Although $E_{i j}$ 's are essentially of empirical nature, their departure from unity may be regarded as a measure of local-composition effects in a nonideal mixture.

From Eqs. (1) to (3) we obtain:

$$
E_{21}=\frac{x_{21} x_{1}}{x_{11} x_{2}}, \quad E_{12}=\frac{x_{12} x_{2}}{x_{22} x_{1}}
$$

Although the actual local composition mole fractions $x_{i j}$ 's are unknown, we can calculate $E_{12}^{L}$ and $E_{21}^{L}$ from Eq. (4) for each datum point as a function of pressure, temperature and composition by substituting the liquid volume in $f(v)$. If the vapor volume is substituted in $f(v), E_{12}^{v}$ and $E_{21}^{v}$ can be obtained.

In this paper, $E_{i j}$ 's were analyzed numerically from a phenomenological aspect in an attempt to obtain a better understanding of the extent of local composition effects in a variety of mixtures.

\section{Significance of Nonconformal Parameters}

All nonconformal parameters $E_{i j}$ 's were calculated from vapor-liquid equilibrium data for 22 polarnonpolar systems, 3 polar-polar systems and 28 nonpolar systems having a great difference in molecular size and shape by using the DDLC-SRK equation (the density-dependent local-composition model combined with the Soave-Redlich-Kwong equation of state). ${ }^{15)}$ Similar tendencies were observed by using the DDLC-PR (Peng-Robinson) ${ }^{13)}$ and DDLC-PT (Patel-Teja) ${ }^{12)}$ equations.

\subsection{Differences between $\boldsymbol{E}_{i j}^{L}$ and $\boldsymbol{E}_{i j}^{v}$}

To investigate the local-composition (LC) effects of both liquid and vapor phases and their pressure and composition dependence, nonconformal parameters $E_{i j}^{L}$ and $E_{i j}^{v}$ for 22 binary systems containing oxygenated hydrocarbons were calculated. The nonconformal parameters $E_{i j}^{L}$ and $E_{i j}^{v}$ for the carbon dioxide and methanol system ${ }^{11}$ are plotted against pressures in Fig. 1.

It is evident that the departure of $E_{12}^{L}$ and $E_{21}^{L}$ from unity is predominant over that of $E_{12}^{v}$ and $E_{21}^{v}$. This means that the local-composition effects in the liquid phase are more prominent than those in the vapor. This tendency is consistent with the results obtained by using the integral equation theory as reported by Lee $e t a l^{\text {7) }}$

Moreover, $E_{i j}^{L}$ 's are almost independent of pressure in a large range, while $E_{i j}^{v}$ 's steadily depart from unity as the pressure increases.

Figure 2 also shows the pressure dependence of the nonconformal parameters for the system ethylene diethylether. ${ }^{10)}$ Although $E_{i j}^{v}$ 's increase steadily with

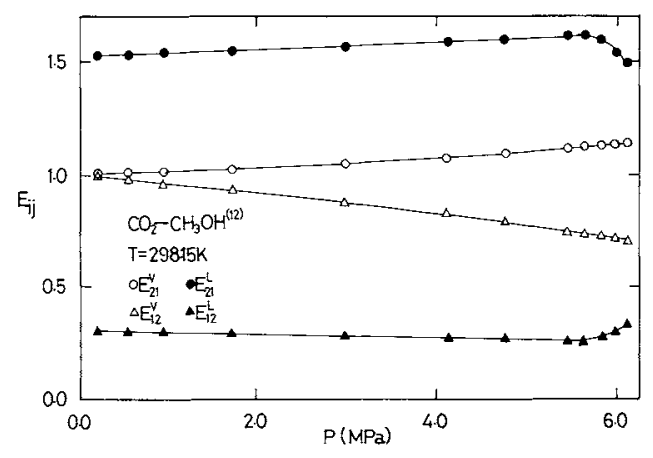

Fig. 1. $E_{12}^{L}, E_{21}^{L}$ and $E_{12}^{v}, E_{21}^{v}$ vs. pressure for the carbon dioxide -methanol system at $298.15 \mathrm{~K}$

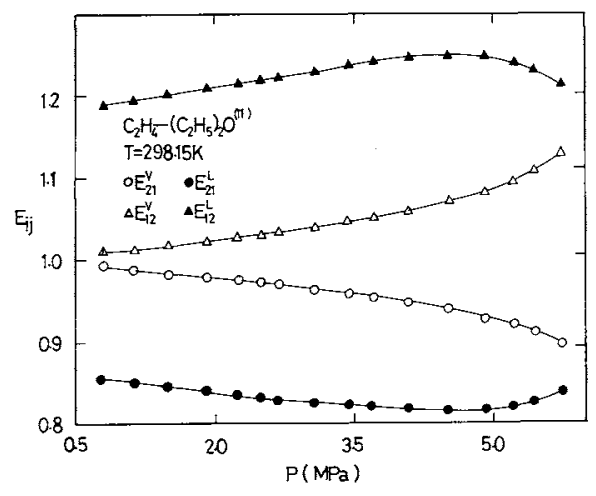

Fig. 2. $E_{12}^{L}, E_{21}^{L}$ and $E_{12}^{v}, E_{21}^{v}$ vs. pressure for the ethylenediethyl-ether system at $298.15 \mathrm{~K}$

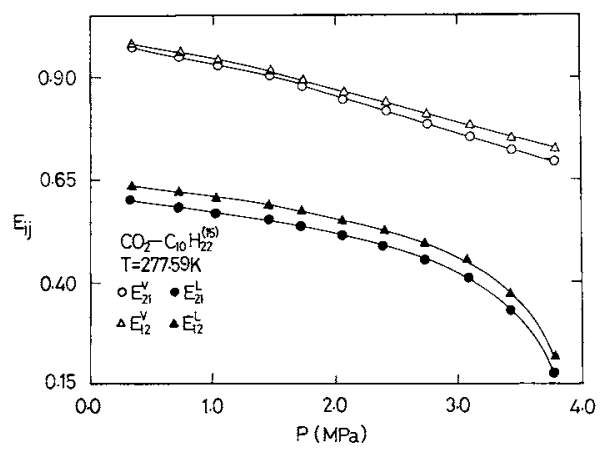

Fig. 3. $E_{12}^{L}, E_{21}^{L}$ and $E_{12}^{v}, E_{21}^{v}$ vs. pressure for the carbon dioxide-decane system at $277.15 \mathrm{~K}$

pressure, $E_{12}^{L}$ exhibits a maximum and $E_{21}^{L}$ a minimum near the pressure of $5 \mathrm{MPa}$.

It can be seen from these figures that for polarnonpolar mixtures, the local composition effect in the liquid phase plays an important role at low pressure, while that in the vapor phase is almost negligible. However, both effects are important in the high pressure range. This phenomenon suggests that the DDLC-EOS unified model should yield a great improvement in the correlation and prediction of vapor-liquid equilibria of polar-nonpolar mixtures. ${ }^{15)}$

\subsection{LC effects in nonpolar asymmetric mixtures}

For mixtures of substances having a great difference in molecular size and shape, such as the carbon dioxide-decane system ${ }^{14)}$ as shown in Fig. 3, 
both $E_{i j}^{L}$ 's and $E_{i j}^{v}$ 's deviate significantly from unity as the pressure increases. This is in contrast to the simulation data of Lee et al. ${ }^{8}$ )

Moreover, as can be seen in Fig. 3, values of $E_{12}^{L}$ and $E_{21}^{L}$, and those of $E_{12}^{v}$ and $E_{21}^{v}$, are quite close together. This indicates that only one parameter $\left(E_{12}=E_{21}\right)$ can be used for both phases as in the case of Mollerup. ${ }^{9}$

\subsection{LC effects in polar-polar mixtures}

For the methanol-water system, ${ }^{4)}$ the nonconformal parameters exhibit a significantly different tendency from those of the polar-nonpolar mixtures and mixtures of different molecular sizes. As shown in Fig. 4, all $E_{i j}^{v}$ 's almost approach unity. This means that local composition effects in the vapor phase may be neglected through the whole pressure range.

Moreover, values of $E_{12}^{L}$ and $E_{21}^{L}$ are not very different from each other. However, as the pressure increases, $E_{i j}^{L}$ 's show a tendency of approaching unity. It is evident that the local composition effects decay at high pressure for this system. A similar tendency is observed for several polar-polar mixtures.

\section{Conclusions}

1. The nonconformal parameters $E_{i j}$ 's of the proposed unified model may serve as a measure of nonrandomness for expressing the local composition effects of a variety of mixtures. For all systems investigated, the local composition effect in the liquid phase is predominant over that in the vapor phase.

2. In the low pressure range, local-composition effects in the vapor phase may be neglected. However, $E_{i j}^{v}$ 's deviate from unity as the pressure increases except for polar-polar mixtures.

3. For polar-nonpolar mixtures, the localcomposition effects in the liquid phase are important although almost independent of pressure in a large range. However, both effects are prominent in the high pressure range.

4. For polar-polar mixtures, the locl-composition effects in the liquid phase are most prominent in the lower pressure range, but tend to approach unity in the high pressure region.

5. For nonpolar systems of substances having a great difference in molecular size and shape, values of $E_{12}^{L}$ and $E_{21}^{L}$, and those of $E_{12}^{v}$ and $E_{21}^{v}$, are quite close together. However, effects of both phases increase significantly with pressure.

\section{Acknowledgments}

This work was supported by the National Natural Science Funds of China.

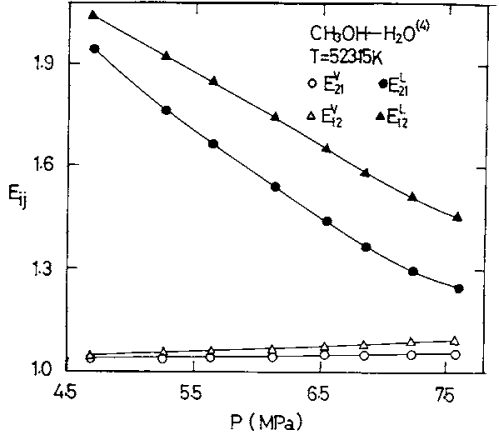

Fig. 4. $E_{12}^{L}, E_{21}^{L}$ and $E_{12}^{v}, E_{21}^{v}$ vs. pressure for the methanol-water system at $523.15 \mathrm{~K}$

\section{Literature Cited}

1) Fischer, J.: Fluid Phase Equilibria, 10, 1 (1985).

2) Gierycz, P., H. Tanaka and K. Nakanishi: Fluid Phase Equilibria, 16, 241 (1984).

3) Gierycz, P. and K. Nakanishi: Fluid Phase Equilibria, 16, 255 (1984).

4) Griswold, J. and S. Y. Wong: Ind. Eng. Chem., 48, Sym. Ser., No. 3, 18 (1952).

5) Haile, J. M.: Fluid Phase Equilibria, 26, 103 (1986).

6) Lee, L. L. and K. E. Starling: Fluid Phase Equilibria, 21, 77 (1985).

7) Lee, L. L., T. H. Chung and L. H. Landis: Fluid Phase Equilibria, 31, 253 (1986).

8) Lee, K.-H., S. I. Sandler and N. C. Patel: Fluid Phase Equilibria, 25, 31 (1986).

9) Mollerup, J.: Fluid Phase Equilibria, 15, 189 (1983).

10) Ohgaki, K., T. Nakatani, T. Saito and T. Katayama: J. Chem. Eng. Japan, 15, 91 (1982).

11) Ohgaki, K. and T. Katayama: J. Chem. Eng. Data, 21, 53 (1976).

12) Patel, N. C. and A. S. Teja: Chem. Eng. Sci, 37, 463 (1982).

13) Peng, P.-Y. and D. B. Robinson: Ind. Eng. Chem., Fundamentals, 15, 59 (1976).

14) Reamer, H. H. and B. H. Sage: J. Chem. Eng. Data, 8, 508 (1963).

15) Zheng, X. Y., G. W. Wu and N. W. Zhang: J. Chem. Eng. Japan, 21, 147 (1988).

\section{Nomenclature}

$\begin{array}{llr}a_{i j}^{o} & =\text { attractive constant for } i-j \text { pair } & {\left[\mathrm{J} \cdot \mathrm{M}^{3} \cdot \mathrm{mol}^{-2}\right]} \\ C_{i j} & =\text { binary interaction parameter } & {[-]} \\ E_{i j} & =\text { nonconformal parameter } & {[-]} \\ P & =\text { pressure } & {[\mathrm{MPa}]} \\ R & =\text { gas constant } & {[\mathrm{J} / \mathrm{K} \cdot \mathrm{mol}]} \\ T & =\text { absolute temperature } & {[\mathrm{K}]} \\ x & =\text { mole fraction of liquid phase } & {[-]} \\ x_{i j} & =\text { local mole fraction for } i-j \text { pair } & {[-]}\end{array}$

〈Superscripts〉

$$
\begin{array}{ll}
L & =\text { liquid phase } \\
o & =\text { conformal mixture } \\
v & =\text { vapor phase }
\end{array}
$$

〈Subscripts〉

$i, j=$ components $i$ and $j$ 